\title{
Seasonal variations in objectively assessed physical activity among people with COPD in two Nordic countries and Australia: a cross-sectional study
}

This article was published in the following Dove Press journal: International Journal of Chronic Obstructive Pulmonary Disease

\author{
Hanne Hoaas ${ }^{1,2}$ \\ Paolo Zanaboni' \\ Audhild Hjalmarsen ${ }^{3,4}$ \\ Bente Morseth ${ }^{5}$ \\ Birthe Dinesen ${ }^{6}$ \\ Angela T Burge ${ }^{7-9}$ \\ Narelle S Cox ${ }^{7,9}$ \\ Anne E Holland ${ }^{7-9}$ \\ 'Norwegian Centre for E-health \\ Research, University Hospital of North \\ Norway, Tromsø, Norway; ${ }^{2}$ Faculty of \\ Health Sciences, UiT The Arctic \\ University of Norway, Tromsø, Norway; \\ ${ }^{3}$ Department of Clinical Medicine, UiT \\ The Arctic University of Norway, \\ Tromsø, Norway; ${ }^{4}$ Department of \\ Pulmonary Medicine, University Hospital \\ of North Norway, Tromsø, Norway; \\ ${ }^{5}$ School of Sport Sciences, UiT The \\ Arctic University of Norway, Tromsø, \\ Norway; ${ }^{6}$ Laboratory of Welfare \\ Technologies - Telehealth \& \\ Telerehabilitation, SMI, Department of \\ Health Science and Technology, Aalborg \\ University, Aalborg, Denmark; ${ }^{7}$ Discipline \\ of Physiotherapy, La Trobe University, \\ Melbourne, Australia; ${ }^{8}$ Department of \\ Physiotherapy, Alfred Health, Melbourne, \\ Australia; ${ }^{9}$ Institute for Breathing and \\ Sleep, Melbourne, Australia
}

Correspondence: Hanne Hoaas Norwegian Centre for E-health Research, University Hospital of North Norway, P.O. Box 35, Tromsø 9038, Norway

Tel +47 48I 05313

Email Hanne.Hoaas@ehealthresearch.no
Purpose: Seasons and weather conditions might influence participation in physical activity and contribute to differences between countries. This study aimed at investigating whether there were differences in physical activity levels between Norwegian, Danish and Australian people with chronic obstructive pulmonary disease (COPD), and establishing if any variations in physical activity were attributable to seasons.

Patients and methods: A cross-sectional study where study subjects were people with COPD who participated in two separate clinical trials: the iTrain study (Norway, Denmark, and Australia) and the HomeBase study (Australia). Physical activity was objectively assessed with an activity monitor; variables were total energy expenditure, number of daily steps, awake sedentary time, light, and moderate-to-vigorous intensity physical activity. Differences in physical activity between countries and seasons were compared, with adjustment for disease severity. Results: In total, 168 participants were included from Norway $(\mathrm{N}=38)$, Denmark $(\mathrm{N}=36)$ and Australia ( $\mathrm{N}=94)$. After controlling for disease severity, time spent in awake sedentary time was greater in Danish participants compared to the other countries (median 784 minutes/day [660-952] vs 775 minutes/day [626-877] for Norwegians vs 703 minutes/day [613-802] for Australians, $P=0.013$ ), whilst time spent in moderate to vigorous physical activity was lower (median 21 minutes/day [4-73] vs 30 minutes/day [7-93] for Norwegians vs 48 minutes/day [19-98] for Australians, $P=0.024$ ). Participants walked more during summer (median 3502 [1253-5407] steps/day) than in spring (median 2698 [1613-5207] steps/day), winter (median 2373 [11454206] steps/day) and autumn (median 1603 [738-4040] steps/day), regardless of geography. The median difference between summer and other seasons exceeded the minimal clinically important difference of 600 steps/day. However, the differences were not statistically significant $(P=0.101)$. Conclusion: After controlling for disease severity, Danish participants spent more time in an awake sedentary state and less time in moderate to vigorous physical activity than their counterparts in Norway and Australia. People with COPD increased their physical activity in summer compared to other seasons. Weather conditions and seasonal variations may influence outcomes in clinical trials and health registries measuring physical activity over time, irrespective of the interventions delivered, and should be taken into account when interpreting results.

Keywords: chronic obstructive pulmonary disease, activity monitoring, population comparison, seasons, weather

\section{Introduction}

Physical inactivity contributes significantly to morbidity and mortality worldwide. ${ }^{1}$ People with chronic obstructive pulmonary disease (COPD) are less physically active than healthy age-matched controls, ${ }^{2,3}$ and physical inactivity and sedentary 
behavior are associated with an increased risk of all-cause mortality in this group. ${ }^{4-7}$ Inactivity is also thought to lead to a more rapid progression of COPD and the development of comorbidities in these individuals. ${ }^{4-6,8}$ Conversely, disease progression, exacerbations and comorbidities may also lead to decreased physical activity. ${ }^{5}$ Given the interplay between physical activity and health in this group, ${ }^{9}$ a physically active lifestyle is recommended for all individuals with COPD. ${ }^{10}$

In healthy people, physical inactivity varies between countries, with populations from high-income countries being the most inactive. ${ }^{11}$ Socioeconomic factors may also have some influence on physical activity among people with COPD. In a study comparing physical activity levels among people with COPD with different socioeconomic and ethnic characteristics, the percentage of Austrians performing less than 30 minutess of moderate to vigorous physical activity per day was $48 \%$ compared with $23 \%$ in a disease severity-matched Brazilian group. ${ }^{12}$

Seasonal variations in terms of duration of daylight time and weather conditions might also affect physical activity levels and could be a confounder when investigating physical activity in COPD. ${ }^{13-17}$ Winter months with cold temperatures have an impact on lung function and the risk of exacerbations. ${ }^{18,19}$ However, extremes of hot weather have also been linked to increased morbidity among those with COPD. ${ }^{19}$ In a study of 190 people with COPD in Canada, temperature was positively related to the number of steps per day, while precipitation was negatively related. ${ }^{16}$ In one study comparing physical activity levels between summer and winter within the same group of people with COPD in Belgium and Brazil, physical activity levels varied considerably according to the season, even when climate differences between winter and summer were less pronounced. ${ }^{17}$

There are a growing number of studies showing that physical activity levels among people with COPD can vary between countries and that seasonal variations can influence physical activity behavior in patients from different world regions. However, the body of evidence is still limited, and variations in physical activity levels among people with COPD across countries and seasons still deserves further investigation.

The objectives of this study were: (1) to investigate whether there were differences in physical activity levels between Norwegian, Danish, and Australian people with COPD and (2) to establish if any variation in physical activity levels was attributable to the seasons (winter, spring, summer, autumn). We hypothesized that Nordic patients might have lower physical activity levels than Australian patients due to lower average temperatures. We also hypothesized a difference in physical activity levels between winter and summer. Exploring physical activity patterns and seasonal variations in physical activity across countries can support interpretation of data from clinical studies where physical activity is an outcome.

\section{Material and methods Study subjects and design}

Study subjects were a cross-sectional convenience sample of participants in two separate clinical trials, the iTrain study and the HomeBase study. Baseline data were used for this analysis. The iTrain study was an international multicenter randomized controlled trial on telerehabilitation for people with COPD in Norway, Denmark and Australia. ${ }^{20}$ The HomeBase study was a randomized controlled trial investigating home-based pulmonary rehabilitation for people with COPD in Australia. ${ }^{21}$ Common inclusion criteria for both trials were a confirmed diagnosis of COPD (forced expiratory volume in 1 second over forced vital capacity ratio/ forced vital capacity $\left.\left(\mathrm{FEV}_{1} / \mathrm{FVC}\right) \leq 0.70\right)$ and age between 40 and 80 years. Participants in these trials were recruited during all seasons. Participants in the HomeBase study were recruited between March 2013 and March 2014. Physical activity was measured in a subgroup of participants recruited from the time when additional funding became available until the end of the trial. The iTrain study recruited from October 2014 to December 2016. The current study included physical activity data in a subgroup of participants recruited from the beginning of the trial to August 2016 when data analysis was initiated.

\section{Settings}

The Tromsø area where the Norwegian participants lived has a humid subarctic continental climate with cool summers and snowy winters. The temperature typically varies from $-7^{\circ} \mathrm{C}$ to $15^{\circ} \mathrm{C}$ over the course of a year, and is rarely below $-13^{\circ} \mathrm{C}$ or above $21^{\circ} \mathrm{C}$. The warm season lasts from June 14 to September 3 with an average daily high temperature above $12^{\circ} \mathrm{C}$. The warmest month of the year is July. The cold season lasts from November 16 to March 31 with an average daily high temperature below $1{ }^{\circ} \mathrm{C}$. The coldest month of the year is February. ${ }^{22}$

The Danish participants lived in the area near Esbjerg, which has a mild humid temperate climate characterized by warm summers. Over the course of a year, the temperature typically varies from $-2^{\circ} \mathrm{C}$ to $21^{\circ} \mathrm{C}$ and is rarely 
below $-8^{\circ} \mathrm{C}$ or above $26^{\circ} \mathrm{C}$. The warm season lasts from May 27 to September 10 with an average daily high temperature above $18^{\circ} \mathrm{C}$. The warmest month of the year is July. The cold season lasts from December 4 to March 5 with an average daily high temperature below $6^{\circ} \mathrm{C}$. The coldest month of the year is February. ${ }^{23}$

The area around Melbourne, where the Australian participants were situated, also has a mild humid temperate climate with warm summers and no dry season. The temperature typically varies from $6^{\circ} \mathrm{C}$ to $26^{\circ} \mathrm{C}$ over the course of a year and is rarely below $3^{\circ} \mathrm{C}$ or above $34^{\circ} \mathrm{C}$. The warm season lasts from December 20 to March 14 with an average daily high temperature above $24^{\circ} \mathrm{C}$. The warmest month of the year is January. The cold season lasts from May 22 to September 3 with an average daily high temperature below $15^{\circ} \mathrm{C}$. The coldest month of the year is July. ${ }^{24}$

\section{Data collection and analysis}

Data on participant characteristics included country, gender, age, body mass index (BMI), number of comorbidities, smoking history, lung function measured by spirometry, ${ }^{25}$ disease severity (I to IV) according to the former staging system of the Global Initiative for Chronic Obstructive Lung Disease (GOLD), ${ }^{10}$ use of long-term oxygen therapy (LTOT), dyspnea measured with the modified Medical Research Council dyspnea scale (MMRC), ${ }^{26}$ and functional walking capacity measured by the 6 minutes walk distance (6MWD). ${ }^{27}$

Physical activity levels were objectively assessed at baseline, prior to any implementation of interventions, with an activity monitor (SenseWear Armband, BodyMedia, Inc., Pittsburgh, PA. USA) which has been also validated for people with COPD. ${ }^{28}$ The SenseWear Armband is an advanced, lightweight microprocessor-based device that is worn over the left triceps. ${ }^{28}$ Participants were asked to wear the activity monitor continuously for 7 consecutive days, except for personal hygiene or other water-based activities. Minute-by-minute output was exported using SenseWear Professional version 8.0 software (BodyMedia, Inc). The first and the last day of recording were excluded from analysis to avoid incomplete measurements which could introduce a bias. Samples without at least one weekend day or without 5 valid days with wear time $\geq 12$ hours days were excluded. ${ }^{13,29}$ All valid days were included in the analysis. Physical activity outcomes were measured total energy expenditure in kilojoules $(\mathrm{kJ})$ per day, total number of steps per day, minutes of awake sedentary time per day, total minutes of light intensity physical activity per day (LIPA), total minutes of moderate-to-vigorous physical activity (MVPA) per day, and total minutes in $\geq 10$ minute bouts of moderate-to-vigorous physical activity (MVPA bouts). Awake sedentary time was defined as activity where the metabolic equivalent was $\leq 1.5 \mathrm{METs}$, and measured sleep was excluded. $^{29}$ Non-wear time was not included in measurement of sedentary behavior. Any activity between 1.5 and 3 METs was defined as LIPA, and activity measured to $\geq 3$ METs was considered MVPA. ${ }^{30}$

Differences in physical activity levels were compared across the three countries (Norway, Denmark and Australia). Seasonal variations were defined according to the meteorological seasons in the Northern Hemisphere and the Southern Hemisphere. The four seasons were defined as follows: winter (from December 1 to February 28 in Norway and Denmark, from June 1 to August 31 in Australia), spring (from March 1 to May 31 in Norway and Denmark, from September 1 to November 30 in Australia), summer (from June 1 to August 31 in Norway and Denmark, from December 1 to February 28 in Australia), and autumn (from September 1 to November 30 in Norway and Denmark, from March 1 to May 31 in Australia).

\section{Statistical analyses}

Descriptive data were reported as median and IQR for continuous variables, and counts and percentages for categorical variables. Normality of distribution was tested with the Kolmogorov-Smirnov test. Differences in participant characteristics between the three countries were compared with Kruskal-Wallis test for continuous variables and chisquared test for categorical variables. A Mann-Whitney test was used as a post hoc test to discover which specific means differed when the overall Kruskal-Wallis result was significant. Log transformation (used for energy expenditure) and cubic root transformation (used for steps, LIPA and MVPA time) were applied to the physical activity variables with a non-normal distribution in order to obtain normally distributed data so that parametric methods for statistical analyses could be performed. No transformation nor statistical analyses were applied to time in MVPA bouts due to the high number of zero values. Values reported in tables are original median and IQR values. Differences in physical activity variables between countries and seasons were compared with one-way ANOVA. A Tukey post hoc test was used to discover which specific means differed where the overall ANOVA result was significant. Between country differences were also adjusted for disease severity $\left(\mathrm{FEV}_{1} \%\right)$ using one-way ANCOVA. 
The combined effect of seasons and countries on physical activity was analyzed with two-way ANOVA. A $P$-value $<0.05$ was considered significant for all tests. All statistical analyses were performed with IBM SPSS Statistics Version 25 (IBM Corporation, Armonk, NY, USA).

\section{Results}

\section{Participant characteristics}

In total 168 participants with moderate to severe COPD from Norway, Denmark, and Australia were included (Table 1). The Australian sample consisted of 61 participants from the HomeBase study and 33 participants from the iTrain study, while samples for Norway $(\mathrm{N}=38)$ and Denmark $(\mathrm{N}=36)$ consisted only of participants from the iTrain study. Demographics for the three groups were generally similar, although the percentage of participants in GOLD stage III and IV (severe and very severe airflow limitation) was higher among the Danish participants. Australian participants had the highest number of comorbidities and Danish participants had a lower functional walking capacity.

\section{Differences in physical activity levels across countries}

All subjects had valid physical activity measurements from 5 days including 1 weekend day with recordings of $\geq 12$ hours per day. There was a statistically significant difference in wear time between all countries $(P=0.001)$. Danish participants wore the activity monitor the most. Physical activity levels were higher for Norwegian and Australian participants compared to Danish participants (Table 2). Danish participants had a lower number of daily steps, less time spent in MVPA, and more awake sedentary time compared to the Australians $(F(2,165)$ $=3.760, P=0.025, F(2,165)=4.347, P=0.014$ and $F(2,165)$ $=4.693, P=0.010$, respectively). After controlling for $\mathrm{FEV}_{1}$, differences in time spent in MVPA and awake sedentary time across countries persisted $(F(2,168)$ $=3.800, P=0.024$ and $F(2,168)=4.431, P=0.013$, respectively), while the difference for daily number of steps was no longer statistically significant.

\section{Effect of seasonal variations on physical activity levels}

The median (IQR) number of steps for all patients was highest in summer $(3,502 ; 1,253-5,407$ steps/day) with lower levels in spring (2,698; 1,613-5,207 steps/day), winter $(2,373 ; 1,145-4,206$ steps/day $)$ and autumn $(1,603 ; 738-4,040$ steps/day), $F(3,164)=2.109, P=0.101$. The difference between summer and other seasons exceeded the minimal clinically important difference of 600 steps/day. ${ }^{31}$ Total MVPA time was also highest during summer. Nevertheless, there were no statistically significant differences among seasons for any of the physical activity variables (Table 3 ).

Results from the two-way ANOVA showed that there was no significant effect for the interaction between country and seasons on the number of steps $(P=0.432)$, with no significant main effect for season $(P=0.273)$, but a significant main effect for country was confirmed $(P=0.018)$. The interaction effect between seasons and country on awake sedentary time was not statistically significant $(P=0.774)$. There was no significant main effect for season $(P=0.936)$, but a significant main effect for country was confirmed $(P=0.044)$. The interaction effect between seasons and country on MVPA time was not statistically significant ( $P=0.801$ ). There was no significant main effect for season $(P=0.633)$, but there was a significant main effect for country $(P=0.042)$.

\section{Discussion}

This study aimed to investigate whether there were differences in physical activity levels between Norwegian, Danish and Australian people with COPD. The results revealed some differences across countries after controlling for disease severity. Danish participants spent more time in an awake sedentary state and less time in MVPA. The study aimed at establishing whether variations in physical activity levels were attributable to seasons. Although it did not reach statistical significance, participants walked more and with higher intensity during summer when compared to spring, winter and autumn, regardless of geography.

Differences in physical activity levels across countries, as seen in this study, have been observed before. A study on participation in physical activity among Austrian and Brazilian people with COPD, suggested that Brazilian participants, due to lower socioeconomic status, may ambulate more for daily activities and to access public transportation than the Austrians who more often had access to their own cars. ${ }^{12}$ In our study, the countries involved have similar prosperity indexes and socioeconomic standards, ${ }^{32}$ while there were differences in disease severity among participants. Disease severity has been shown to have a weak-tomoderate positive association with reduced physical activity 
Table I Characteristics of participants with COPD from Norway, Denmark and Australia

\begin{tabular}{|c|c|c|c|c|c|}
\hline & $\begin{array}{l}\text { Norway } \\
(\mathrm{N}=38)\end{array}$ & $\begin{array}{l}\text { Denmark } \\
(\mathrm{N}=36)\end{array}$ & $\begin{array}{l}\text { Australia } \\
(\mathrm{N}=94)\end{array}$ & $P$-value & Post hoc ${ }^{a}$ \\
\hline Sex, male & $24(63 \%)$ & $20(55 \%)$ & $52(55 \%)$ & 0.696 & \\
\hline Age, year & $66(63-72)$ & $63(6 \mathrm{I}-68)$ & $66(60-73)$ & 0.211 & \\
\hline BMI, kg/m² & $28.4(24.0-33.1]$ & $25.6(22.9-28.0)$ & $26.0(22.0-30.5)$ & 0.066 & \\
\hline Comorbidities, number & $2(I-3)$ & $2(0-2)$ & $3(2-4)$ & $<0.001$ & $\begin{array}{l}A U \text { vs } N O=0.009 \\
D K \text { vs } A U=0.001\end{array}$ \\
\hline $\begin{array}{l}\text { Smoking status } \\
\text { Current smoker } \\
\text { Ex-smoker } \\
\text { Never smoked }\end{array}$ & $\begin{array}{l}14(37 \%) \\
24(63 \%) \\
0(0 \%)\end{array}$ & $\begin{array}{l}13(36 \%) \\
23(64 \%) \\
0(0 \%)\end{array}$ & $\begin{array}{l}18(19 \%) \\
73(78 \%) \\
3(3 \%)\end{array}$ & 0.085 & \\
\hline Smoking, pack years & $24(15-40)$ & $40(25-46)$ & $45(31-56)$ & $<0.001$ & $\begin{array}{l}\text { DK vs } N O=0.003 \\
A U \text { vs } N O=0.001\end{array}$ \\
\hline $\mathrm{FEV}_{1} / \mathrm{FVC}$ & $52.8(44.0-59.0)$ & $51.5(43.0-62.5)$ & $43.5(34.0-56.0)$ & 0.002 & $\begin{array}{l}A U \text { vs } N O=0.008 \\
D K \text { vs } A U=0.002\end{array}$ \\
\hline $\mathrm{FEV}_{\mathrm{I}}$, liters & $1.32(0.97-1.82)$ & $0.92(0.69-1.11)$ & $1.13(0.86-1.50)$ & $<0.001$ & $\begin{array}{l}D K \text { vs } N O=0.001 \\
D K \text { vs } A U=0.002\end{array}$ \\
\hline $\mathrm{FEV}_{1}, \%$ predicted & $50.7(38.7-63.8)$ & $32.5(25.0-41.0)$ & $44.0(32.0-62.0)$ & $<0.001$ & $\begin{array}{l}D K \text { vs } N O=0.001 \\
D K \text { vs } A U=0.001\end{array}$ \\
\hline FVC, \% predicted & $74.7(67.0-90.0)$ & $65.5(48.5-78.0)$ & $74.0(62.0-90.0)$ & 0.011 & $\begin{array}{l}D K \text { vs } \mathrm{NO}=0.013 \\
\text { DK vs } A U=0.004\end{array}$ \\
\hline $\begin{array}{l}\text { Disease severity } \\
\text { GOLD II } \\
\text { GOLD IIII } \\
\text { GOLD IV }\end{array}$ & $\begin{array}{l}20(53 \%) \\
\mathrm{II}(29 \%) \\
7(18 \%)\end{array}$ & $\begin{array}{l}3(8 \%) \\
15(42 \%) \\
18(50 \%)\end{array}$ & $\begin{array}{l}40(43 \%) \\
38(40 \%) \\
16(17 \%)\end{array}$ & $<0.001$ & \\
\hline Use of LTOT, yes & $5(13 \%)$ & $9(25 \%)$ & $12(13 \%)$ & 0.204 & \\
\hline $\begin{array}{l}\text { MMRC } \\
\text { Score } 0 \\
\text { Score } 1 \\
\text { Score } 2 \\
\text { Score } 3 \\
\text { Score } 4\end{array}$ & $\begin{array}{l}2(5 \%) \\
\text { II (29\%) } \\
\text { I2 (32\%) } \\
\text { II (29\%) } \\
2(5 \%)\end{array}$ & $\begin{array}{l}2(6 \%) \\
10(28 \%) \\
13(36 \%) \\
10(28 \%) \\
1(3 \%)\end{array}$ & $\begin{array}{l}\text { I (I\%) } \\
40(43 \%) \\
27(29 \%) \\
23(24 \%) \\
3(3 \%)\end{array}$ & 0.642 & \\
\hline 6MWD, meters & $416(350-480)$ & 318 193-383) & $427(358-480)$ & $<0.001$ & $\begin{array}{l}D K \text { vs } N O=0.001 \\
D K \text { vs } A U=0.001\end{array}$ \\
\hline Lowest $\mathrm{SpO}_{2}$ during $6 \mathrm{MWD}, \%$ & $90(86-93)$ & $90(86-92)$ & $90(86-93)$ & 0.978 & \\
\hline Max HR during 6MWD, beats per minute & $112(99-127)$ & $115(106-122)$ & $113(102-122)$ & 0.889 & \\
\hline SOB end of 6MWD, Borg CR-10 scale & $5(4-7)$ & $3(2-3)$ & $4(3-5)$ & $<0.001$ & $\begin{array}{l}D K \text { vs } N O=0.001 \\
D K \text { vs } A U=0.002\end{array}$ \\
\hline RPE end of 6MWD, Borg CR-10 scale ${ }^{b}$ & $4(2-6)$ & $3(2-4)$ & $3(2-5)$ & 0.432 & \\
\hline Gait aid, yes & $2(5 \%)$ & $6(17 \%)$ & $8(9 \%)$ & 0.218 & \\
\hline
\end{tabular}

Notes: ${ }^{a}$ Only significant comparisons are listed. ${ }^{b}$ For the Australian participants, this variable was only calculated for the 33 participants in the iTrain study. Data is presented as median (IQR) for continuous variables, and counts (percentages) for categorical variables. A pack year is defined as twenty cigarettes smoked every day for one year. Abbreviations: BMI, body mass index; FEV , forced expiratory volume in the first second; FVC, forced vital capacity; LTOT, long-term oxygen therapy; MMRC, modified version of the Medical Research Council Scale; $6 \mathrm{MWD}, 6$ minutes walking distance; $\mathrm{SpO}_{2}$, peripheral capillary oxygen saturation; $\mathrm{HR}$, heart rate; SOB, rating of perceived shortness of breath; RPE, rating of perceived exertion for leg fatigue; DK, Denmark; NO, Norway; AU, Australia. 
Table 2 Physical activity among participants from Norway, Denmark and Australia

\begin{tabular}{|c|c|c|c|c|c|c|}
\hline & $\begin{array}{l}\text { Norway } \\
N=38\end{array}$ & $\begin{array}{l}\text { Denmark } \\
\mathrm{N}=36\end{array}$ & $\begin{array}{l}\text { Australia } \\
\mathrm{N}=94\end{array}$ & $P$-value & Post hoc & $\begin{array}{l}\text { P-value after } \\
\text { controlling } \\
\text { for FEV }\end{array}$ \\
\hline Wear time, minutes/day & $\begin{array}{l}I, 36 \mid \\
(I, 340-I, 4 \mid 4)\end{array}$ & $\begin{array}{l}I, 429 \\
(I, 408-1,437)\end{array}$ & $\begin{array}{l}I, 418 \\
(I, 40 I-I, 429)\end{array}$ & 0.001 & $\begin{array}{l}\text { DK vs NO\&AU } \\
\text { NO vs AU }\end{array}$ & \\
\hline Energy expenditure, $\mathrm{kJ} / \mathrm{day}$ & $\begin{array}{l}9790 \\
(8,237-11,754)\end{array}$ & $\begin{array}{l}8439 \\
(7,772-9,641)\end{array}$ & $\begin{array}{l}8320 \\
(7,569-10,843)\end{array}$ & 0.266 & & 0.288 \\
\hline $\begin{array}{l}\text { Steps, } \\
\text { number/day }\end{array}$ & $\begin{array}{l}1672 \\
(1,020-3,839)\end{array}$ & $\begin{array}{l}1534 \\
(778-3,194)\end{array}$ & $\begin{array}{l}2916 \\
(1,316-4,986)\end{array}$ & 0.025 & DK vs AU & 0.133 \\
\hline Awake sedentary time, minutes/day & $\begin{array}{l}775 \\
(626-877)\end{array}$ & $\begin{array}{l}784 \\
(660-952)\end{array}$ & $\begin{array}{l}703 \\
(613-802)\end{array}$ & 0.010 & DK vs $A U$ & 0.013 \\
\hline $\begin{array}{l}\text { Total LIPA, } \\
\text { minutes } / \text { day }^{\mathrm{a}}\end{array}$ & $\begin{array}{l}158 \\
(8|-2| 9)\end{array}$ & $\begin{array}{l}178 \\
(124-234)\end{array}$ & $\begin{array}{l}208 \\
(132-249)\end{array}$ & 0.388 & & 0.422 \\
\hline Total MVPA, minutes/day & $\begin{array}{l}30 \\
(7-93)\end{array}$ & $\begin{array}{l}21 \\
(4-73)\end{array}$ & $\begin{array}{l}48 \\
(19-98)\end{array}$ & 0.014 & DK vs $A U$ & 0.024 \\
\hline Time in MVPA bouts, minutes/day & $\begin{array}{l}8 \\
(0-30)\end{array}$ & $\begin{array}{l}4 \\
(0-26)\end{array}$ & $\begin{array}{l}7 \\
(0-24)\end{array}$ & n.a. & & n.a. \\
\hline
\end{tabular}

Notes: DK vs NO\&AU, NO vs $A U$ and $D K$ vs $A U=P$-value $\leq 0.050$, only significant comparisons are listed. ${ }^{a}$ LIPA for the Australian sample was available for the 33 participants in the iTrain study only. Data are median (IQR).

Abbreviations: LIPA, light-intensity physical activity; MVPA, moderate-to-vigorous physical activity; n.a., nonapplicable; DK, Denmark; NO, Norway; AU, Australia.

in patients with COPD. ${ }^{5,33}$ This partially explained the differences in physical activity in the current study, as the Danish participants, who had higher sedentary time and lower MVPA time, also had more severe COPD than their counterparts in Norway and Australia. As disease severity may influence physical activity, it is important to take this into account in clinical studies, and ensure that participants are properly stratified to achieve similarity between groups in multicenter and multinational trials.
For the healthy population, the country of residence seems to influence self-reported physical activity more than in people with COPD. According to the Global Observatory for Physical Activity, 53\% of the Norwegian population and $76 \%$ of the Danish population report being physical active compared with only $43 \%$ of the Australian population. ${ }^{34}$ However, these findings are based on selfreported data and may not be as accurate as our objectively measured data as large variations between self-reported

Table 3 Physical activity in the different seasons

\begin{tabular}{|c|c|c|c|c|c|}
\hline & $\begin{array}{l}\text { Winter } N=50 \\
(N O=I 2 ; D K=8 ; \\
A U=30)\end{array}$ & $\begin{array}{l}\text { Spring } N=40 \\
(N O=I I ; D K=8 ; \\
A U=2 I)\end{array}$ & $\begin{array}{l}\text { Summer } N=22 \\
(N O=0 ; D K=4 ; \\
A U=18)\end{array}$ & $\begin{array}{l}\text { Autumn } N=56 \\
(N O=15 ; D K=16 ; \\
A U=25)\end{array}$ & $\begin{array}{l}P \text { - } \\
\text { value }\end{array}$ \\
\hline $\begin{array}{l}\text { Energy expenditure, } \\
\mathrm{kJ} / \text { day }\end{array}$ & $\begin{array}{l}9075 \\
(7,796-10.297)\end{array}$ & $\begin{array}{l}8571 \\
(7748-1 \mid 783)\end{array}$ & $\begin{array}{l}8491 \\
(7.642-1(164)\end{array}$ & $\begin{array}{l}8442 \\
(7.261-10314)\end{array}$ & 0.181 \\
\hline Steps, & 2373 & 2698 & 3502 & 1603 & 0.101 \\
\hline number/day & $(1,145-4,206)$ & $(1,6 \mid 3-5,207)$ & $(1,253-5,407)$ & $(738-4,04)$ & \\
\hline Awake sedentary time, min- & 721 & 755 & 700 & 735 & 0.796 \\
\hline utes/day & $(608-868)$ & $(635-901)$ & $(6 \mid 7-801)$ & $(620-824)$ & \\
\hline Sleep time, & 410 & 362 & 365 & 401 & 0.982 \\
\hline minutes/day & $(316-463)$ & $(316-45 I)$ & $(3|7-48|)$ & $(3 \mid 4-463)$ & \\
\hline Total LIPA, & 160 & 197 & 159 & 177 & 0.487 \\
\hline minutes/day ${ }^{a}$ & $(102-237)$ & $(150-255)$ & $(99-25 I)$ & $(106-230)$ & \\
\hline Total MVPA, & 39 & 38 & 62 & 27 & 0.326 \\
\hline minutes/day & (15-88) & $(20-100)$ & $(\mathrm{II}-108)$ & $(8-90)$ & \\
\hline Time in MVPA bouts, & 9 & 7 & 7 & 5 & n.a. \\
\hline minutes/day & $(0-23)$ & $(0-34)$ & $(2-25)$ & $(0-25)$ & \\
\hline
\end{tabular}

Notes: aLIPA for the Australian sample was available for the 33 participants in the iTrain study only. Data are presented as median (IQR).

Abbreviations: LIPA, light-intensity physical activity; MVPA, moderate-to-vigorous physical activity; n.a., nonapplicable; NO, Norway; DK, Denmark; AU, Australia. 
and accelerometer-measured physical activity and sedentary time have been reported. ${ }^{35}$

In our study, the difference in awake sedentary time and time spent in MVPA persisted across countries after controlling for disease severity. Danish participants, who spent significantly longer periods of the day in sedentary activities and less time walking at higher intensities, had significantly lower functional walking capacity (indicated by 6MWD) than participants from other countries. There is a moderate association between physical activity and physical capacity. ${ }^{5}$ In the current study, participants from Norway and Australia had a median walking distance of $>400 \mathrm{~m}$ on the 6 MWD and achieved $\geq 30$ minutes of MVPA, whereas Danish participants walked a median of $<400$ meters and did not meet the value of $\geq 30$ minutes of MVPA which is recommended by the American College of Sports Medicine. ${ }^{36}$ Such correlation between physical capacity and intensity of physical activity has previously been observed by Pitta et al. ${ }^{2}$ However, high physical capacity does not always translate into higher levels of physical activity, as physical activity is also influenced by psychological factors like habit, self-efficacy and health beliefs. ${ }^{37,38}$

Reducing sedentary time can decrease cardiovascular risk in other patient groups. ${ }^{39}$ As many patients with COPD have cardiovascular comorbidities, ${ }^{40}$ strategies to reduce sedentary time may be clinically relevant in COPD. ${ }^{41}$ Targeting sedentary behavior can also be effective in improving the ability to stand up from a seated position among older adults, thus improving physical functioning. ${ }^{42}$ A recent review suggests that future trials should examine sedentary time as an outcome when assessing physical activity interventions as this may have clinical benefits for people with COPD. ${ }^{41}$ In the current study, variations in step count across the year were not offset by changes in awake sedentary time, as sedentary time was unchanged all year. Strategies that target sedentary behavior might have a potential for increasing overall physical activity.

Climate and variations in weather conditions following the different seasons may influence levels of daily physical activity in COPD. ${ }^{5}$ Studies have reported a lower number of steps during rainy and colder days, in winter and during extreme summer heat. ${ }^{14,16,17,43,44}$ A recent study of people with COPD residing in Canada reported that an increase in daytime temperature of $10^{\circ} \mathrm{C}$ translated into 316 more daily steps (6.6\% of mean steps/day) whereas rainfall of $10 \mathrm{~mm}$ had a negative effect of 175 less daily steps $(3.6 \%$ of mean steps/day). ${ }^{16}$ The current study was conducted in three countries with climate zones spanning from an Arctic climate with cold summers and cold winters to tropically influenced climate with warm summers and mild winters. Participants with COPD walked more during summer than during spring, winter and autumn, regardless of location. Results did not reach statistical significance perhaps due to the modest sample size in each group. However, the overall difference between summer (3,502 steps/day) and winter $(2,373$ steps/day) exceeded the minimal clinical important difference (between 600 and 1,100 steps/day) in daily step count after pulmonary rehabilitation. ${ }^{31}$ An improvement of more than 600 steps/day after pulmonary rehabilitation is also reported to reduce the risk of hospitalization in patients with COPD. ${ }^{31}$ We therefore consider the difference of 1,129 daily steps between summer and winter to be of clinical relevance. In the current study, time spent in MVPA during winter was also found to be $37 \%$ lower than in summer. Interestingly, another study found a significant reduction of the time spent actively during winter when compared to summer among both Brazilian and Belgian people with COPD. Such a difference was even more evident in patients from Brazil (20\% vs $12 \%$ in Belgium), although Brazil has lower variations in temperature between summer and winter than Belgium. ${ }^{17}$ In the current study, the data collected during winter had a higher percentage of participants from the Nordic countries than those collected during summer. This may, in part, explain the difference with the findings from Furlanetto et al. ${ }^{17}$

Seasonal differences have implications for clinical trials that measure physical activity over time, as the season in which the measurement is taken may influence outcomes irrespective of any intervention delivered. The effect of temperature and season on daily steps has recently been reported in a 3-month physical activity intervention trial on people with COPD. ${ }^{45}$ An increase in daily steps was found in subgroup analysis of both a group receiving a pedometer and web-based support and of a group receiving a pedometer intervention alone during the transition from spring to summer. During the transition from summer to autumn, the group with web-based support experienced an increase in daily step count from baseline, while the group using only pedometer had a significant decline. ${ }^{45}$ The influence of seasonal variations on physical activity habits may be relevant for selected patient groups, such as COPD, as well as for the healthy population. Results from multinational trials as well as health registries where physical activity is an outcome should take into account differences in physical activity 
patterns due to seasonal variations both if the trial is performed across countries or within one country.

\section{Study strengths and limitations}

This study included a cross-sectional convenient sample of 168 participants from three countries. Study subjects were participants enrolled in two separate trials using common inclusion criteria, methods and algorithms for objectively measurements of physical activity. This allowed us to investigate differences in physical activity across countries based on a larger sample than that from a single trial. Differences in disease severity between participants in the different countries were found, and as a consequence controlled for. The study also has some limitations. Danish participants wore the activity monitor for longer each day, and by this, they might have recorded longer time in sedentary activities than their counterparts might. Sample power was not computed beforehand, and the lower number of Nordic patients with physical activity data collected during summer may have influenced the results on seasonal variations. Recruitment during summer was low due to summer holiday both for healthcare personnel supporting the recruitment procedures and potential participants. We recommend that future studies investigating seasonal variation will be attentive to include enough participants in each season. The majority of the physical activity variables in the dataset were characterized by a non-normal distribution. We therefore transformed those variables to achieve normal distribution and use parametric tests. However, similar results were achieved by use of nonparametric tests. These data represent cross- sectional observations rather than assessment of the longitudinal impact of seasons on a given individual. Further studies taking into account seasonal effects on changes in physical activity over time are required.

\section{Conclusion}

In this cross-sectional study, time spent in awake sedentary time was greater in Danish participants compared to the Norwegian and Australian participants after controlling for disease severity, whilst time spent in MVPA was lower. The number of steps for all patients was highest in summer with lower levels in spring, winter and autumn, regardless of geography. In particular, the overall difference between summer and winter exceeded the minimal clinical important difference in daily step count after pulmonary rehabilitation. Weather conditions and seasonal variations may influence outcomes in clinical trials and health registries measuring physical activity over time, irrespective of the interventions delivered, and should be taken into account when interpreting results.

\section{Ethics approval and informed consent}

Only patients who had volunteered and provided written informed consent in accordance with the Declaration of Helsinki were included in this study. The iTrain study was approved by the Regional Committee for Medical and Health Research Ethics in Norway (2014/676/REK nord), the North Denmark Region Committee on Health Research Ethics (N-20140038), and the Alfred Hospital Human Research Ethics Committee (289/14). The HomeBase study was approved by the Alfred Hospital Human Research Ethics Committee (261/11), Austin Health Human Ethics Committee (H2011/04364) and La Trobe University Faculty of Health Sciences Human Ethics Committee (11-134). Approval to combine data from the HomeBase study with the iTrain study has been received. Trial registration: Clinical Trials registry NO.: NCT02258646 and NCT01423227.

\section{Data sharing statement}

The datasets used and/or analyzed during the current study are available from the corresponding author on reasonable request.

\section{Acknowledgments}

The authors thank Bjørn Straume, Marthe Larsen, Fred Gotliebsen and Stein Olav Skrøvseth for fruitful discussions regarding the statistical analysis in the study. Ms. Hanne Hoaas is the recipient of a European Respiratory Society Fellowship (STRTF 2015). The authors thank the Esbjerg Healthcare Center and The Pulmonary Ward at Southwest Hospital in Esbjerg, the Department of Pulmonary Medicine at the University Hospital of North Norway in Tromsø, Alfred Health and Austin Health in Melbourne. The publication charges for this article have been funded by a grant from the publication fund of UiT The Arctic University of Norway. This study was supported by a short-term research training fellowship offered by the European Respiratory Society (STRTF 2015). The iTrain study was funded by the Research Council of Norway (Project Grant 228919/H10) and the Northern Norway Regional Health Authority (Project Grants HST1117-13 and HST1118-13). The HomeBase study was funded by Lung Foundation Australia and National 
Health and Medical Research Council project grant 1046353

\section{Author contributions}

$\mathrm{PZ}, \mathrm{AH}, \mathrm{BD}$, and $\mathrm{AEH}$ are responsible for the iTrain study protocol. AEH is responsible for the HomeBase study protocol. $\mathrm{HH}, \mathrm{PZ}$, and $\mathrm{AEH}$ contributed to the conception and design of the current study. HH, PZ, BD, ATB, NSC, and $\mathrm{AEH}$ contributed to the acquisition of data. All authors contributed toward data analysis, drafting and critically revising the paper, gave final approval of the version to be published, and agree to be accountable for all aspects of the work.

\section{Disclosure}

The authors declare that they have no competing interests. Dr Narelle Cox reports honorarium paid by Boehringer Ingelheim for workshop delivery regarding pulmonary rehabilitation and exercise in COPD. The authors report no other conflicts of interest in this work.

\section{References}

1. Kohl HW 3rd, Craig CL, Lambert EV, et al. The pandemic of physical inactivity: global action for public health. Lancet. 2012;380(9838):294-305.

2. Pitta F, Troosters T, Spruit MA, Probst VS, Decramer M, Gosselink R. Characteristics of physical activities in daily life in chronic obstructive pulmonary disease. Am J Respir Crit Care Med. 2005;171(9):972-977. doi:10.1164/rccm.200407-855OC

3. Park SK, Richardson CR, Holleman RG, Larson JL. Physical activity in people with COPD, using the National health and nutrition evaluation survey dataset (2003-2006). Heart Lung. 2013;42(4):235-240. doi:10.1016/j.hrtlng.2013.04.005

4. Troosters T, van der Molen T, Polkey M, et al. Improving physical activity in COPD: towards a new paradigm. Respir Res. 2013;14:115. doi:10.1186/1465-9921-14-19

5. Watz H, Pitta F, Rochester CL, et al. An official European respiratory society statement on physical activity in COPD. Eur Respir J. 2014;44 (6):1521-1537. doi:10.1183/09031936.00046814

6. Waschki B, Kirsten A, Holz O, et al. Physical activity is the strongest predictor of all-cause mortality in patients with COPD: a prospective cohort study. Chest. 2011;140(2):331-342. doi:10.1378/chest.10-2521

7. Furlanetto KC, Donária L, Schneider LP, et al. Sedentary behavior is an independent predictor of mortality in subjects with COPD. Respir Care. 2017;62(5):579-587. doi:10.4187/respcare.05306

8. Van Remoortel H, Hornikx M, Demeyer H, et al. Daily physical activity in subjects with newly diagnosed COPD. Thorax. 2013;68 (10):962-963. doi:10.1136/thoraxjnl-2013-203534

9. Waschki B, Kirsten AM, Holz O, et al. Disease progression and changes in physical activity in patients with chronic obstructive pulmonary disease. Am J Respir Crit Care Med. 2015;192(3):295306. doi:10.1164/rccm.201501-00810C

10. Goldcopd.org [homepage on the Internet]. The Global Initiative for Chronic Obstructive Lung Disease (GOLD). Global strategy for the diagnosis, management and prevention of chronic obstructive pulmonary disease 2018 Report; 2018 Available from: https://goldcopd. org/wp-content/uploads/2017/11/GOLD-2018-v6.0-FINAL-revised20-Nov_WMS.pdf. Accessed August 14, 2018.
11. Hallal PC, Andersen LB, Bull FC, Guthold R, Haskell W, Ekelund U. Global physical activity levels: surveillance progress, pitfalls, and prospects. Lancet. 2012;380(9838):247-257. doi:10.1016/S0140-6736(12) 60646-1

12. Pitta F, Breyer M-K, Hernandes NA, et al. Comparison of daily physical activity between COPD patients from Central Europe and South America. Respir Med. 2009;103(3):421-426. doi:10.1016/j.rmed.2008.09.019

13. Demeyer H, Burtin C, Van Remoortel H, et al. Standardizing the analysis of physical activity in patients with COPD following a pulmonary rehabilitation program. Chest. 2014;146(2):318. doi:10.1378/chest.13-1968

14. Sewell L, Singh SJ, Williams JEA, Morgan MD. Seasonal variations affect physical activity and pulmonary rehabilitation outcomes. $J$ Cardiopulm Rehabil Prev. 2010;30(5):329-333. doi:10.1097/ HCR.0b013e3181e175f2

15. Sumukadas D, Witham M, Struthers A, McMurdo M. Day length and weather conditions profoundly affect physical activity levels in older functionally impaired people. J Epidemiol Community Health. 2009;63(4):305-309. doi:10.1136/jech.2008.080838

16. Balish SM, Dechman G, Hernandez P, et al. The relationship between weather and objectively measured physical activity among individuals with COPD. J Cardiopulm Rehabil Prev. 2017;37(6):445-449. doi:10.1097/HCR.0000000000000244

17. Furlanetto KC, Demeyer H, Sant 'Anna T, et al. Physical activity of patients with COPD from regions with different climatic variations. Copd. 2017;14(3):276-283. doi:10.1080/15412555.2017.1303039

18. Koskela HO. Cold air-provoked respiratory symptoms: the mechanisms and management. Int J Circumpolar Health. 2007;66(2):91-100.

19. Hansel NN, McCormack MC, Kim V. The effects of air pollution and temperature on COPD. Copd. 2016;13(3):372-379. doi:10.3109/ 15412555.2015.1089846

20. Zanaboni P, Dinesen B, Hjalmarsen A, et al. Long-term integrated telerehabilitation of COPD patients: a multicentre randomised controlled trial (iTrain). BMC Pulm Med. 2016;16(1):126. doi:10.1186/s12890-0160276-3

21. Holland AE, Mahal A, Hill CJ, et al. Home-based rehabilitation for COPD using minimal resources: a randomised, controlled equivalence trial. Thorax. 2017;72(1):57-65. doi:10.1136/thoraxjnl-2016-208514

22. Weatherspark.com [homepage on the Internet]. San Francisco, United States: cedar Lake Ventures: average weather for Tromsø, Norway. Available from: https://weatherspark.com/y/ 84211/Average-Weather-in-Tromssø-Norway-Year-Round. Accessed October 1, 2016

23. Weatherspark.com [homepage on the Internet]. San Francisco, United States: cedar Lake Ventures: average weather for Esbjerg, Denmark. Available from: https://weatherspark.com/averages/28824/EsbjergSyddanmark-Denmark. Accessed October 1, 2016.

24. Weatherspark.com [homepage on the Internet]. San Francisco, United States: cedar Lake Ventures: average weather for Melbourne, Australia. Available from: https://weatherspark.com/averages/34069/ Melbourne-Victoria-Australia. Accessed: October 1, 2016.

25. Miller MR, Hankinson J, Brusasco V, et al. Standardisation of spirometry. Eur Respir J. 2005;26(2):319-338. doi:10.1183/09031936.05.00034805

26. Stenton C. The MRC breathlessness scale. Occup Med. 2008;58 (3):226-227. doi:10.1093/occmed/kqm 162

27. Holland AE, Spruit MA, Troosters T, et al. An official European respiratory Society/American thoracic society technical standard: field walking tests in chronic respiratory disease. Eur Respir J. 2014;44(6):1428-1446. doi:10.1183/09031936.00150314

28. Patel SA, Benzo RP, Slivka WA, Sciurba FC. Activity monitoring and energy expenditure in COPD patients: a validation study. Copd. 2007;4(2):107-112. doi:10.1080/15412550701246658

29. Byrom B, Rowe DA. Measuring free-living physical activity in COPD patients: deriving methodology standards for clinical trials through a review of research studies. Contemp Clin Trials. 2016;47:172-184. doi:10.1016/j.cct.2016.01.006 
30. Norton K, Norton L, Sadgrove D. Position statement on physical activity and exercise intensity terminology. J Sci Med Sport. 2010;13 (5):496-502. doi:10.1016/j.jsams.2009.09.008

31. Demeyer H, Burtin C, Hornikx M, et al. The minimal important difference in physical activity in patients with COPD. PLoS One. 2016;11(4):e0154587. doi:10.1016/j.rmed.2017.07.057

32. Prosperity.com [homepage on the Internet]. London, United Kingdom: legatum Institute Foundation: legatum prosperity index TM; 2016. Available form: http://www.prosperity.com/rankings. Accessed March 23, 2017.

33. Troosters T, Sciurba F, Battaglia S, et al. Physical inactivity in patients with COPD, a controlled multi-center pilot-study. Respir Med. 2010;104(7):1005-1011. doi:10.1016/j.rmed.2010.01.012

34. Globalphysicalactivityobservatory.com [homepage on the Internet]. Global observatory for physical activity: country cards; 2017. Available from: http:/www.globalphysicalactivityobservatory.com/ country-cards/. Accessed June 22, 2017.

35. Dyrstad SM, Hansen BH, Holme IM, Anderssen SA. Comparison of selfreported versus accelerometer-measured physical activity. Med Sci Sports Exerc. 2014;46(1):99-106. doi:10.1249/MSS.0b013e3182a0595f

36. Haskell WL, Lee IM, Pate RR, et al. Physical activity and public health: updated recommendation for adults from the American college of sports medicine and the American heart association. Med Sci Sports Exerc. 2007;39(8):1423-1434.

37. Thorpe O, Kumar S, Johnston K. Barriers to and enablers of physical activity in patients with COPD following a hospital admission: a qualitative study. Int J Chron Obstruct Pulmon Dis. 2014;9(1):115128. doi:10.2147/COPD.S54457

38. Burtin C, Langer D, Van Remoortel H, et al. Physical activity counselling during pulmonary rehabilitation in patients with COPD: a randomised controlled trial. PLoS One. 2015;10(12):e0144989. doi:10.1371/journal.pone.0144989
39. Wilmot EG, Edwardson CL, Achana FA, et al. Sedentary time in adults and the association with diabetes, cardiovascular disease and death: systematic review and meta-analysis. Diabetologia. 2012;55 (11):2895-2905. doi:10.1007/s00125-012-2677-z

40. Maclay JD, McAllister DA, MacNee W. Cardiovascular risk in chronic obstructive pulmonary disease. Respirology. 2007;12 (5):634-641. doi:10.1111/j.1440-1843.2007.01136.x

41. Lahham A, McDonald CF, Holland AE. Exercise training alone or with the addition of activity counseling improves physical activity levels in COPD: a systematic review and meta-analysis of randomized controlled trials. Int J Chron Obstruct Pulmon Dis. 2016;11:3121-3136. doi:10.2147/COPD.S121263

42. Gibbs BB, Brach JS, Byard T, et al. Reducing sedentary behavior versus increasing moderate-to-vigorous intensity physical activity in older adults. J Aging Health. 2017;29(2):247-267. doi:10.1177/ 0898264316635564

43. Togo F, Watanabe E, Park H, Shephard RJ, Aoyagi Y. Meteorology and the physical activity of the elderly: the Nakanojo study. Int $J$ Biometeorol. 2005;50(2):83-89. doi:10. 1007/s00484-005-0277-z

44. Alahmari AD, Mackay AJ, Patel AR, et al. Influence of weather and atmospheric pollution on physical activity in patients with COPD. Respir Res. 2015;16(1):71. doi:10.1186/s12931-015-0229-z

45. Wan ES, Kantorowski A, Homsy D, et al. Promoting physical activity in COPD: insights from a randomized trial of a web-based intervention and pedometer use. Respir Med. 2017;130:102-110. doi:10.1016/j.rmed.2017.07.057

\section{Publish your work in this journal}

The International Journal of COPD is an international, peer-reviewed journal of therapeutics and pharmacology focusing on concise rapid reporting of clinical studies and reviews in COPD. Special focus is given to the pathophysiological processes underlying the disease, intervention programs, patient focused education, and self management protocols. This journal is indexed on PubMed Central, MedLine and CAS. The manuscript management system is completely online and includes a very quick and fair peer-review system, which is all easy to use. Visit http://www.dovepress.com/testimonials.php to read real quotes from published authors. 